\section{\& \\ Ministriles novohispanos. Obras del manuscrito I9 de la catedral de Puebla de los Ángeles}

\author{
CD, Ensemble La Danserye (Catedral de Jaén: Sociedad \\ Española de Musicología/El Patrimonio Musical \\ Hispano, 20I2).*
}

por

JAZMÍN RINCÓN**

El papel que desempeñaron los ministriles del siglo Xvi ha sido siempre un tema controversial en la musicología y la historiografía de la música. A ello ha contribuido desde la terminología para llamarlos "géneros de músicos y cantores que hay en los monasterios, con trompetas y dulzainas, y pífanos, $y$ viguelas de arco, y rabeles", hasta el hecho de que el repertorio para instrumentos que ha sobrevivido sea muy escaso, tanto en España como, más acentuadamente, en la Nueva

* Texto recibido el I6 de julio de 20I5; aceptado el 20 de agosto de 2015 .

** Becaria del doctorado en Historia del Arte.
España. El que dicho repertorio sea tan exiguo en nuestro país tiene diversas explicaciones complementarias, tales como que la música instrumental de la época estaba ligada a la tradición oral y a la práctica mnemotécnica aprendida en el Viejo Mundo y fusionada con las costumbres locales; que el lenguaje musical no contaba aún con una escritura idiomática para instrumentos, por lo cual dependía casi por completo del repertorio vocal; y también que los cuadernos de ministriles eran propiedad de los músicos, por lo cual, en su mayoría, no sobrevivieron fuera de los archivos catedralicios.

A este respecto y como parte de la colección El Patrimonio Musical Hispano de la Sociedad Española de Musicología (SEdeM), dedicada al siglo xvi, la agrupación española de instrumentos de viento La Danserye presenta un proyecto fonográfico de sumo valor e interés: la interpretación históricamente informada de una gran parte de las obras que contiene el manuscrito in del archivo musical de la Catedral de Puebla, México; éste es, aparentemente, el único libro para uso de ministriles con música del siglo XVI y XVII, localizado hasta la fecha en catedrales del Nuevo Mundo.

El Ms ig es el libro de coro número ig de la Catedral de Puebla. Por desgracia, hoy día no es posible tener acceso a él directamente en el archivo de esta institución. En el catálogo 
de Thomas E. Stanford ${ }^{\mathrm{I}}$ se registró como si todas las obras contenidas en él fuesen de Hernando Franco, y se agrega la signatura LiPol xIx (Libro de Polifonía XIx) que está en el Rollo de microfilm núm. 46 en el Museo Nacional de Antropología e Historia, en donde se puede consultar y fotocopiar. Aunque la catalogación de Stanford aclara que son "obras sin texto", las canciones a cuatro voces de Pedro Rimonte sí lo tienen en el cantus.

Me gustaría mencionar que, además de dicho libro, existen casos en la polifonía novohispana, y en realidad en todo el repertorio polifónico renacentista, en los que alguna de las líneas vocales, en general el bajo, no incluyen el texto escrito, aunque comparten tanto la textura melódica contrapuntística como la estructura fraseológica de las demás voces. Esto sugiere que el texto se añadía de manera natural a la hora de la ejecución, como parte del uso consuetudinario. En el caso del MS I9, además de que son las cuatro voces las que carecen de texto en la mayoría de los casos, cuenta con otras características paradigmáticas que nos inducen a creer que se trata de un manuscrito para uso de ministriles, como lo sustentan las notas al programa del disco. Un ejemplo de esto, entre otros, sería la presencia de versos para instrumentos de la tradición del alternatim y obras profanas en un libro de coro que se caracteriza por contener música sacra, como lo son todos los libros catedralicios con tal formato. Sin embargo, el mismo hecho de que el libro tenga elementos propios de la función litúrgica y que tipologías como los versos se alternen

I. Thomas E. Stanford, Catálogo de los acervos musicales de las catedrales metropolitanas de México y Puebla de la Biblioteca Nacional de Antropología e Historia y otras colecciones menores (México: Instituto Nacional de Antropología e Historia, 2002), 362. con el canto, me hace dudar si la línea divisoria entre música instrumental y vocal, que plantea tan conclusivamente el presente proyecto, era realmente así y no una combinación de ambas en la práctica.

No obstante, uno de los aspectos más interesantes que nos presenta el disco es ciertamente su enfoque historicista o "interpretación históricamente informada”, el cual, al poner en diálogo la investigación musicológica con la práctica interpretativa de la música, busca discursos complementarios por medio de cuestiones tan variadas como la lectura original de las fuentes históricas sin intermediación de la transcripción; las muchas combinaciones posibles de instrumentos consort en función del carácter del repertorio; la afinación y la construcción de éstos; y la recreación espacial del hábitat que dichos instrumentos solían tener. En efecto, en una época en la que la llamada interpretación históricamente informada ${ }^{2}$ se ha convertido ya en una práctica institucionalizada en el ámbito global y se ha instalado en países como México cual eco de una voz descontextualizada, el presente proyecto surge de manera alterna y como un necesario retorno a la búsqueda del sentido local originario que hace falta tanto en el mundo de la música antigua como en el de hoy, homogeneizado en gran parte por las instituciones y la misma industria fonográfica.

Por lo mismo, cabe destacar el trabajo del musicólogo español Javier Marín López, quien, además de ser el responsable de la investigación del proyecto, en los textos del CD presenta un muy completo contexto historiográfico particularmente ilustrativo respecto a la presencia y actuación de

2. HIP: Historically Informed Performance. 
ministriles en el virreinato de la Nueva España. Para esto, la notable forma en que interrelaciona las fuentes europeas y americanas no es sino una muestra de su fructífera carrera y de su trabajo por largas temporadas en diversos archivos de ambos continentes, de cuya producción cabe destacar la autoría del libro - y originalmente tesis doctoral-: Música y músicos entre dos mundos: la Catedral de México y sus libros de polifonía (siglos XVI-XVIII), 3 vols. (Universidad de Granada, 2007); o su papel como director del Festival de Música Antigua de Úbeda y Baeza, dedicado a la recuperación del patrimonio musical español e hispanoamericano.

Por su parte, el Ensemble La Danserye ha ofrecido, desde su creación en 1998, más de 400 conciertos en festivales y ciclos de música antigua y ha participado en las grabaciones de siete CDS, especializados en el periodo renacentista de la música y más puntualmente en la recuperación del patrimonio musical español, estos intérpretes provienen (como menciona Javier Marín en el texto introductorio) "de una saga familiar en cuyo seno iniciaron el aprendizaje de estos instrumentos a la vieja usanza: comenzaron en su niñez de una forma intuitiva y solidaria, aprendieron música tocando directamente el repertorio, se construyeron sus propias flautas y cornetas y se ejercitaron indistintamente en todos los instrumentos de viento." Esto último es quizá uno de los aspectos más atractivos y que más llamaron mi atención de la presente grabación, pues supone un trabajo de ejecución fuera del ámbito técnico y los estudios académicos: la búsqueda de la tradición de la música del pasado mediante una tradición interpretativa española del presente; la de los hermanos Pérez Valera, quienes tañen instrumentos varios y tan variados en sonoridad como las cornetas, los sacabuches, las flautas de pico, los orlos y los bajoncillos.

El manuscrito contiene 74 composiciones ( 34 obras sacras y 40 profanas), de las cuales se seleccionaron en la presente grabación 29 a fin de que representaran "la variedad y riqueza del contenido del manuscrito, tanto en autores, procedencias y cronologías, como en géneros, funciones y estilos". Así, cabe destacar las canciones a cinco voces atribuidas a Philippe Rougier (ca. I56I-1569), tres de las cuales, junto con una canción anónima sin título, así como un igualmente anónimo madrigal Occhi miei carecen de transmisiones en fuentes ibéricas, por lo cual se rescatan y graban por primera vez en este CD. Además de Rougier, la selección nos presenta una paleta muy amplia de compositores que, entre otras cosas, evidencia las relaciones y el enriquecimiento musical que se dio entre el Viejo y el Nuevo Mundo en los siglos XVI y XVII: desde autores locales como Hernando Franco (ca. 1530-1585), hasta autores españoles como Francisco Guerrero (1528-1599) o franco-flamencos como Orlando di Lasso (I532-I594), entre otros.

Uno de los principales problemas de los estudios en torno a la música del pasado es precisamente lo referente a la lectura de las fuentes pues, de manera paradójica, el registro de la escritura pone una distancia entre la obra y el músico que en los siglos XVI y XVII distaba mucho de ser lo que es hoy día. En ese sentido, el presente proyecto fonográfico no sólo saca a la luz un libro de la Catedral de Puebla, México, hasta hoy olvidado —el MSI9-, sino que también representa una seria búsqueda multidisciplinaria; un acercamiento a lo que pudo haber sido el colectivo de los ministriles en aquella época por medio de diversas y necesarias interpretaciones. 